\title{
PERFORMANCE OF THE INTEGRAL ROCKET-RAMJETS
}

\author{
A.M.SARHAN", M.A.EL-SENBAWI", S.M.ABDEL-GHANY
}

\section{ABSTRACT}

The work alms at the experimental and theoretical determination of the effect of the air addition on the performance of solid propellant Integral Rocket-Ramjet Motors IRRM's. An experimental investigation was carried aut to determine the specidic Impulse dependence on the air equivalence ratio, using an 80 mm motor with exchangeable external and intermediate nozzles. Air inlets and secondary combustion chamber were kept unchanged. The ducted air by ram effect was simulated in this ground testing by feeding pressurized air into the secondary combustion chamber. The experimental investigation showed that the motor specific impulse was increased by about $85 \%$ when the air equivalence ratio was increased from zero to about 0.7 .

A simple one dimensional mathematical model of a solid propellant IRRM at steady state is presented. The numerical calculations based on the presented model showed good agreement with the test results.

\section{INTRODUCTION}

Only Integral Rocket Ramjet Motors IRRM's, due to their high specific impulse, high speed, continuous thrust and compactness can uniquely meet the urgent needs of the next generation atmospheric missiles, [1]. The October 1973 War "YOM KIPPUR" convincingly demonstrated the effectiveness of the IRR surface-to-air tactical missiles. The Egyptian alr defence inflected sharp losses on the lsraeli fighters using the Russian missile SAM-6, which employs the solid propellant IRRM variant.

The main variants of IRRM, as illustrated in Fig.1 are solid propellant IRRM, liquid propellant IRRM, solid propellant IRRM with additional liquid fuel injection into the secondary combustion chamber, and scram-jet rocket motor, where supersonic combustion is allowed in the secondary combustion chamber, [1].

* Ph.D., Dep. of Rockets, M.T.C., Cairo.

* Ph.D. Head of Dep. of Rockets, M.T.C., Cairo.

* * Prof. Dep. of Mechanical Power, Ain Shams University, Cairo. 
The performance of IRRM compared to that of rockets, turbotans, and turbojets is illustrated in Fig. 2 and Fig.3.

According to the purpose of the study, theoretical analysis of IRRM can be tackled by one of the following two approaches:

\section{Quasi One Dimensional Analysis}

We assume that the angle of the air inlet and the length of the secondary combustion chamber are chosen so that the incompletely burned gases and the ducted air are completely mixed and reacted. For this case, the integral forms of mass, momentum, and energy and the are to be solved together with the equation of state compute thews of the gas mixture. This approach is useful to compute the overall performance of the IRRM.

\section{I1. Three-Dimensional Axisymmetric Analysis}

Assuming that the turbulent mixing can be mathematically expressed in an accurate mathematical form, the flow field inside the secondary combustion chamber can be fully investigated by momentum, energy, turbulentorms of the equations of mass, scale and chemical kinetics of thetic energy, turbulence length equation of state. Due to the the reactions, together with the gases are much faster than thei fact that the reaction rates of equations expressing the reactiong rates, [2], the group of without having significant error, [3, can be completely ignored the number of partial different, 3,4$]$. That assumption reduces ntial equations and the stiffness out theoretically cal solution. This approach is useful to find corresponding required combustor angle of air inlets and the of the IRRM can be obtained.

The present work is an experimental and theoretical investigation into the solid propellant IRRM's. The first approach is employed to study the effect of air addition on their performance.

\section{ONE-DIMENSIONAL MATHEMATICAL MODEL}

Following Ramanujachary's model, [5], the solid propellant IRRM can be divided into four main parts as shown schematically in chamber, These are the air diffuser, the primary combustion chamber, the secondary combustion chamber and the nozzle. The analysis is based on one dimensional flow with the assumption of no heat transfer from the hot gases to the combustor walls.

\section{The Air Diffuser}

The IRRM often uses four axisymmetrical conical air diffusers, similar to those of jet engines. The function of the air diffuser 
is to decelerate and compress the afr flow into the secondary combustion chamber. In ground testing, the air diffusers are replaced by an alr feeding system as it will be explained in the experimental part.

\section{The Primary Combustion Chamber}

Here, a fuel-rich propellant is burned producing incompletely burned gases. At steady siate, assuming small gas velocity, constant chamber volume, negligibly small pressure variation along the propellant grain, isentropic process and frozen flow, the stagnation pressure pop inside this zone has the form

$$
P_{o p}=\left[K_{1} u_{0} C^{*} e_{p} \operatorname{Exp}\left(K_{T}\left(T_{p}-T_{N}\right)\right]\right] 1 /(1-n)
$$

where $k_{j}$ is the blocking factor defined as the ratio of burning surtace to throat area, $e_{p}$ is the specific mass of the propeliant, $C^{\text {k }}$ is the characteristic velocity of the propellant. $u_{0}, K_{T}$ and $n$ are propellant constants, and $T_{p}$ and $T_{N}$ are the actual and normal propellant temperatures.

The conditions at the throat. (which are in the same time the inlet conditions of the secondary combustion chamber) can be given by

$$
\begin{aligned}
& \therefore_{2 g}=\left(P_{0 g} A_{2 g}\right) / C^{*} \\
& T_{2 g}=T_{0 g}\left[2 /\left(k_{1}+1\right)\right] \\
& P_{2 g}=P_{0 g}\left[2 /\left(k_{1}+1\right)\right] k_{1} /\left(k_{1}+1\right) \\
& v_{2 g}=\left[2 k_{1} R_{1} T_{\circ g} /\left(k_{1}+1\right)\right] 0.5
\end{aligned}
$$

where Tog $1 \mathrm{~s}$ the adlabatic flame temperature of the propellant.

\section{The sacondary Combustion Chamber}

For simplicity, it is assumed that the ducted air and the Incompletely burned gases are subjected successively to processes of mixing, pressure loss, and heat addition at distinct zones.

Hixing zone

In the mixing zone, the incompletely burned gases and the ducted air (both of known parameters $p, Q, T, v, c_{p}$ and $R$ ) are $m i x \in d$ together. It is required to compute the gas parameters after complete mixing. The thermodynamic properties of the mixture $R_{3}$. ${ }^{c} p, 3$ and $k_{3}$ are obtained as follows

$$
R_{3}=R_{u} / \mu_{3}
$$


where

$$
\begin{aligned}
u_{3} & =1 /\left(x_{a} / \mu_{a}+x_{p} / \mu_{p}\right) \\
x_{a} & =\dot{m}_{a} /\left(\dot{m}_{2 a}+\dot{m}_{2 p}\right) \\
x_{p} & =\dot{m}_{p} /\left(\dot{m}_{2 a}+\dot{m}_{2 p}\right) \\
c_{p, 3} & =x_{a} c_{p, 2 a}+x_{p} c_{p, 2 p} \\
k_{3} & =c_{p, 3} /\left(c_{p, 3}-R_{3}\right)
\end{aligned}
$$

and

The equations of continuity, momentum and energy are

$$
\begin{aligned}
& \dot{m}_{2 \mathrm{a}}+\dot{m}_{2 \mathrm{p}}=\mathrm{A}_{3} v_{3} \mathrm{p}_{3} /\left(\mathbb{R}_{3} \mathrm{~T}_{3}\right)=\dot{m}_{3} \\
& p_{2 a} A_{2 a} / 00 s B+\dot{m}_{2 a} v_{2 a} \cos \theta+p_{2 p} A_{2 p}+\dot{m}_{2 p} v_{2 p} \\
& =\mathrm{p}_{3} \mathrm{~A}_{3}+\dot{\mathrm{m}}_{3} \mathrm{~V}_{3} \\
& i_{2 a}\left(c_{p}, 2 a T_{2 a}+0.5 v_{2 a}{ }^{2}\right)+i_{2 p}\left(c_{p}, 2 p T_{2 p}+0.5 v_{2 p}{ }^{2}\right) \\
& =\dot{m}_{3}\left(\sigma_{p, 3} T_{3}+0.5 v_{3}^{2}\right)
\end{aligned}
$$

These equetions are solved simultaneously to get $v_{3}, p_{3}$ and $T_{3}$. Pressure ings zone Assuming an adiabatic frictional loss ( $1 . e . T_{04}=$ Tos), the
pressure loss 1 , expressed as

$$
P_{03}-P_{04}=0.5 k e_{3} v_{3}^{2}
$$
where $K$ is the pressure loss ractor which lies within the range
$1<K<4$, $\{63$. Eq. 15 can be modifled to be

$$
P_{04} / p_{03}=1-\left[\left(k_{3} / 2\right)\left(k_{3} M_{3}^{2}\right)\left(1+0.5\left(k_{3}-1\right) M_{3}^{2}, k_{3} /\left(1-k_{3}\right)\right]\right.
$$

From the equations of state and continulty we get

$$
\begin{aligned}
& p_{04} / p_{03}= \\
& \left(M_{3} / M_{4}\right)\left[\left(1+0.5\left(K_{3}-1\right) M_{4}^{2}\right) /\left(1+0.5\left(K_{3}-1\right) M_{3} 2\right)\right]\left(k_{3}+1\right) / 2\left(k_{3}-1\right)
\end{aligned}
$$

The values of $M_{4}$ and Po4 can be obtained by solving Eq. 16 and Heat addition zone

The mixture of air and incompletely burned gases flowing from section 4 is ready to burn in the heat addition zone. This initial its initial composition as in section 3 , and its Initial stagnation temperature $T_{04}=T_{03}$. So, the equilibrium composition and the values of ${ }^{2} T_{0}, R_{5}$ and $k_{5}$ can now be calculated using a suitable program of thermochemical calculations [7]. The program is valid for range of ofrom zero 


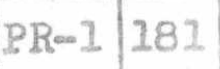

to the stolchiometric value for the propellant. We proceed for the determination of $M_{5}$ and $P_{0}$ considering a simple constant area heat addition process as follows

From equations of state and continuity we get

$$
\begin{aligned}
P_{5} / P_{4}= & \left(M_{4} / M_{5}\right)\left[\left(K_{4} R_{5} T_{05}\right) /\left(K_{5} R_{4} T_{04}\right)\right]^{0.5} \times \\
& \times\left[\left(1+0.5\left(K_{4}-1\right) M_{4} 2\right) /\left(1+0.5\left(K_{5}-1\right) M_{5} 2\right)\right] 0.5
\end{aligned}
$$

In the absence of wall irlction loss, the momentum and state equations yield

$$
P_{5} / P_{4}=\left(1+K_{4} M_{4}^{2}\right) /\left(1+K_{5} M_{5}^{2}\right)
$$

Together with the 1sentrople low relation

$$
\begin{aligned}
& \qquad P_{05}=P_{5}\left(2+0.5\left(k_{5}-1\right) M_{5}{ }^{2}, k_{5} /\left(k_{5}-1\right)\right. \\
& \text { the values of } M_{5} \text {, P } P_{5} \text { and } P_{05} \text { can be determined. }
\end{aligned}
$$

The Nozzle

The treatment is based on quasi one-dimensional, isentropic frozen llow through the nozzle. The throat area $A$ t corresponding to the calculated stagnation pressure and the characteristic velootty $C^{\text {म }}$ (caloulated for $T_{05}, R_{5}$ and $k_{5}$ ) is expressed as

$$
A^{*}=C^{*} m_{5} / p_{05}
$$

If $A_{G}>A^{*}$, the nozzle will not be choked and no supersonic flow can be attained by this nozzle. If $A_{G}<A^{\not k}$ the ndzzle will be choked but the gas should be accumulated in the secondary chamber for a translent period. The stagnation pressure is thus increased to a new equilibrium stagnation pressure so that the inlet mass flow rate to the secondary chamber should be equal to the mass flow rate of the gases exhausted through the nozzle throat.

$$
\dot{\mathrm{m}}_{6}=\dot{\mathrm{m}}_{5}
$$

The new equilibrium pressure pos corresponding to the throat area $A_{6}$ could be obtained from

$$
i_{6}=p_{05} A_{6} / C^{*}
$$

The gas exhaust velocity $v_{7}$ is expressed as

$$
v_{7}=\left[\left(2 k_{5} R_{5} T_{05} /\left(k_{5}-1\right)\right)\left(1-\left(p_{7} / p_{05}\right)\left(k_{5}-1\right) / k_{5}\right)\right]^{0.5}
$$

P7 is the pressure at the exit section, its value is chosen to be equal to $\mathrm{Pa}_{\mathrm{a}}$ at some altitude for which the maximum global thrust gain is achieved, [8].

The area ratio $A_{7} / A_{6}$ is given by 


$$
A_{7} / A_{6}=\frac{\Gamma\left(k_{5}\right)}{\left(p_{7} / p_{05}\right)^{1 / k_{[}}\left[( 2 k _ { 5 } / ( k _ { 5 } - 1 ) ) \left(1-\left(p_{7} / p_{05}\right)^{\left.\left(k_{5}-1\right) / k_{5}\right]^{0.5}}\right.\right.}
$$

The thrust of the IRRM can be expressed as

$$
F=\eta_{n}\left[\dot{m}_{6} v_{7}-\dot{m}_{a} v_{1}+A_{7}\left(p_{7}-p_{a}\right)\right]
$$

where $i_{n}$ is the nozzle efficiency.

The specific impulse $i_{s p}$ is given by

$$
1_{E F}=\left(1 / m_{p}\right)_{t_{19}}^{t_{k}} F \cdot d t
$$

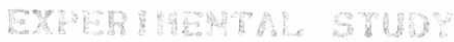

A series of tests were carried out using an $80 \mathrm{~mm}$ test motor chacged with a sueb-rich double-base propeliant. The ducted air to the secondary combustion chamber by ram effect was simulated in the tests by feeding a pressurized alr into the inlets of the secondary combustion chamber from a pressurized air reservoir. The osed prapellant had the following data

Sumary formula: $\mathrm{C}_{23.495} \mathrm{H}_{31.936} \mathrm{O}_{34.75} \quad \mathrm{H}_{9.415}$

Heat of formation: $H_{p}=-2413.5 \mathrm{~kJ} / \mathrm{Kg}$

Burning rate (in si units):

$$
U=2.294 \times 10^{-7} p^{0.674} \text { Exp }\left[0.00448\left(T_{p}-20\right)\right]
$$

Simple thermochemical calculation of the propellant combustion, assuming five ges products, gave the following sesults for the gas products:

- Composition of the gas products given in gram moles per $1 \mathrm{~kg}$ of the propellant:

$\mathrm{CO}_{2}: 3.555, \mathrm{CO}: 19.939, \mathrm{H}_{2}: 8.268$ Adlabatic flame temperature

- Molecular mass

- Gas constant

- Ratio of specific heats

- Specific heat at constant pressure

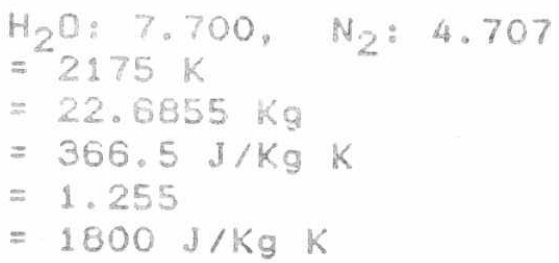

\section{Test Rig}

Fig. 5 shows the general scheme of the test rig which had been used. The basic parts of the test rig are the test motor 1, the thrust test bed 2, the air feeding system $3-8$, the pickups 9-13, and the signal conditioning and recording system 14-17. 
The test motor was designed to secure the following:

- A speciflc primary chamber is to be mounted for each length of the propellant grain, namely 10,15 and $20 \mathrm{~cm}$.

- The critical area of the intermediate nozzle is set for each test so that the working pressure of the primary combustion chamber is kept almost the same.

- The adr is introduced to the secondary combustion chamber through pour axisymmetrio clrcumferential circular air inlets. with ifxed inclination $45^{\circ}$ to ensure optimum mixing, $[9]$.

- The length-ta-diameter ratio of the secondary combustion chamber is chosen L/d $=8$ in order to have complete reaction with minimum pressure losses, [10].

- A set of nozzles of the same expansion ratio, but different critical axeas are used to get almost the same working pressure at secondary combustion chamber.

To sinulate the ducted alr during fight, two E0-11ter reservols with compressed alr at 30 bar were used to supply the secondary combustion chamber with alr through four flexible hoses.

The IRRM was mounted on a horizontal type swinging test bed as shown in Fig.6. The thrust and pressure at different positions (alr reservolis, air inlets to the secondary combustor, primary and secondary combustors) were measured by stäaln-gauge transducers with irequency response up to $20 \mathrm{kHz}$. The expected measurement error by these transducers is less than $0.5 \%$.

The mass flow of a Ir was computed from the measured parameters of air in the reservoir at the moments of alr flow start, motor ignition and burn-out which are described by subscripts "st", "ig" and "k" respectively. These events are marked on the pressure-time records, providing an appropriate means for time determination. Assuming adiabatic process, the mass consumption of air ma (from ignition to burn-out) is calculated from

$$
\mathrm{m}_{\mathrm{a}}=\left(\mathrm{V} / \mathrm{R}_{\mathrm{a}} T_{s t}\right)\left[p_{i g}\left(p_{i g} / p_{s t}\right)(1-k) / k_{-} p_{k}\left(p_{k} / p_{s t}\right)(1-k) / k\right]
$$

where $R_{a}, k, V$ are the air gas constant, ratio of specific heats and reservolis volume respectively.

The average mass flow rate $\dot{m}_{a}$ is computed form

$$
\dot{m}_{a}=m_{a} /\left(t_{k}-t_{i g}\right)
$$

The difference in the mass flow rate of air from one test to another was kept in narrow limits. A significant control of equivalence ratio $\alpha$ was done by controlling the mass flow rate of the incompletely burned gases flowing to the seconciary combustion chamber. The average value of $\alpha$ is expressed as

$$
\alpha=m_{a} / m_{p}
$$

where $m_{p}$ is the mass of propellant charge. 


\section{Experimenta】 Results}

Five maln tests were performed to investigate the effect of the air equiyalence ratio on the specific impulse of the IRRM. The first four tests were carried out with air addition, while the fifth test was done without air at all to be a basis for the comparison. The numerical values of the tested cases are summarized in Table 1. A sample of the obtained thrust and pressure time traces is presented in Fig.7. The figure shows a constant primary combustor pressure and a linearly varying air reservoli pressure which indicate constant mass flow rates of the incompletely burned gases and the air.

Test data show that the specific impulse is augmented as a result of air infection into the secondary combustion chamber. The speciflc impulse was incieased from 1404 to $2600 \mathrm{~m} / \mathrm{s}$ with an $85 \%$ increase, when the equivalence ratio was increased from zero to 0.686 . Further increase may be expected as far as complete combustion has not yet been attalned. The low secondery combustion chamber pressure, (resulting from low possible attained diffuser pressure) leads to limited expansion ratio through the nozzle. Consequently, IRRM's are more suitable for the flight at high altitudes where greater expansion ratios can be reached.

Tabla 1. Test data

\begin{tabular}{|c|c|c|c|c|c|}
\hline Parameter & 1 & 2 & 3 & 4 & 5 \\
\hline $\begin{array}{l}\text { Mass of propellant, } \mathrm{Kg} \\
\text { internediate nozzle }\end{array}$ & 0.4 & 0.4 & 0.585 & 0.785 & 0.600 \\
\hline $\begin{array}{l}\text { throat diameter , m } \\
\text { Watn nozzle throat }\end{array}$ & 11.5 & 11.5 & 13.0 & $\$ 4.5$ & 21.5 \\
\hline diameter, $\mathrm{nm}$ & 25.5 & 24.5 & 25.5 & 30.0 & 24.5 \\
\hline $\begin{array}{l}\text { Area Ratio } \mathrm{A}^{/ \mathrm{A}_{t}} \\
\text { Ar inlet average }\end{array}$ & 4.15 & 4.16 & 4.15 & 4.0 & 4.16 \\
\hline $\begin{array}{l}\text { pressure, bar } \\
\text { Adr reservoir pressure }\end{array}$ & 12.2 & 10.2 & 10.5 & 9.85 & - \\
\hline $\begin{array}{l}\text { at ignition, bar } \\
\text { Afr seservoir pressure }\end{array}$ & 15.6 & 15.6 & 15.6 & 13.0 & - \\
\hline at burn-out, bar & 14.0 & 14.0 & 14.4 & 12.0 & - \\
\hline Mass of inlet air, $\mathrm{Kg}$ & 0.276 & 0.137 & 0.102 & 0.090 & 0.000 \\
\hline $\begin{array}{l}\text { Air equivalence ratio, } \\
\text { Primary chamber average }\end{array}$ & 0.686 & 0.343 & 0.174 & 0.114 & 0.000 \\
\hline $\begin{array}{l}\text { pressure, bar } \\
\text { Secondary chamber average }\end{array}$ & 58.8 & 58.8 & 45.0 & 54.0 & 78.8 \\
\hline pressure, bar & 9.0 & 8.7 & 9.0 & 7.0 & 17.0 \\
\hline Average thrust, $\mathrm{N}$ & 866.6 & 650.0 & 668.6 & 980.7 & 773.5 \\
\hline Time of function, $S$ & 1.200 & 1.20 & 1.400 & 1.240 & 1.090 \\
\hline Total impulse, NS & 1039.9 & 780 & 936.0 & 1215 & 842.5 \\
\hline Specific impulse, $N \mathrm{~S} / \mathrm{Kg}$ & 2600 & 1950 & 1600 & 1548 & 1404 \\
\hline
\end{tabular}




\section{COMPUTED RESULTS}

Numerlcal computations were carried out for summarized in table 2 . using the presented the tested cases. mathematical model These results are

\section{Table 2. Results of Theoretical calculations}

\begin{tabular}{|c|c|c|c|c|c|c|c|c|}
\hline $\begin{array}{c}\text { Test } \\
\text { No. }\end{array}$ & $\alpha$ & ${ }_{\mathrm{K}}^{\mathrm{T}}$ & $K_{5}$ & $\begin{array}{l}R_{5} \\
J / K g \cdot K\end{array}$ & $\begin{array}{l}p_{o 5} \\
\text { bar }\end{array}$ & $\begin{array}{l}v_{7} \\
m / s\end{array}$ & $\begin{array}{l}F \\
N\end{array}$ & ${ }_{\mathrm{i}}^{\mathrm{i} \mathrm{p}}$ \\
\hline $\begin{array}{ll}\text { Test } & 1 \\
\text { Test } & 2 \\
\text { Test } & 3 \\
\text { Test } & 4 \\
\text { Test } & 5\end{array}$ & $\begin{array}{l}0.687 \\
0.3432 \\
0.1742 \\
0.1144 \\
0.0\end{array}$ & $\begin{array}{l}2550 \\
2350 \\
2275 \\
2200 \\
2175\end{array}$ & $\begin{array}{l}1.235 \\
1.245 \\
1.250 \\
1.253 \\
1.255\end{array}$ & $\begin{array}{l}323.0 \\
331.3 \\
346.5 \\
352.6 \\
366.5\end{array}$ & $\begin{array}{l}12.86 \\
11.76 \\
12.64 \\
12.56 \\
17.18\end{array}$ & $\begin{array}{l}1950 \\
1941 \\
1938 \\
1920 \\
1957\end{array}$ & $\begin{array}{r}815.5 \\
625.8 \\
703.4 \\
1018.8 \\
919.5\end{array}$ & $\begin{array}{l}2650.0 \\
2033.7 \\
1803.0 \\
1726.8 \\
1672.9\end{array}$ \\
\hline
\end{tabular}

Compar 1 son between the theoretical and experimental values of the specific ixpulse as function of the alr equivalence ratio is presented in Fig.8. It can be noticed that the difrerence between the theoretical and experimental results 15 relatively great for small yalues of $\alpha$ and $1 t$ gradually gets smaller as the values of $\alpha$ increase. This can be explained by the tact that the mathematical model assumes no heat transfer through the walls to the surroundings, while the thick-walled test motor absorbs a considerable amount of heat. This amount can be neglected relative to the great liberated heat for higher values of a. However, the heat absorbed by the walls tends to be comparable with the low heat liberated for small values of a. Taking into consideration that real motors normally operate at higher equivalence ratios, and that they usually have thinner walls compared to test motors, one can come to the conclusion that the presented model provides an efficient tool for practical appilication.

Theoretical investigation was carried out for the dependence of specific impulse and adiabatic tlame temperature in the secondary combustor for the range of ofrom zero to the stoichlometric value $\alpha=1.8$. Results are presented in Fig.9 and Fig.10 respectively. The specific impulse showed a monotonic increase with the increase of $\alpha$ in the full investigated range. On the other hand, the temperature increased steadily with $\alpha_{\text {, }}$ up to $\alpha=0.7$ then it showed approximately constant value. This can be explained by the dilution effect of the nitrogen content in air. Such behavior is favorable in real application from the point of view of thermal effects on combustor walls. 


\section{CONCLUSION}

The specific impulse is augmented as a result of the air injection into the secondary combustor. The specific impulse showed an Increase of $85 \%$ when the air equivalence ratio was increased from zero to 0.7 . Computed values for the test cases showed good agreeament with the experimental results. in particular, for higher values of a. Further theoretical investigations for the full range of a from zero to 1.8 (which is the stoichiometric equivalence ratio for the used propellant) showed that the specific impulse increases monotonically with a. On the other hand, the adiabatic ilame temperature of the seaction In the secondary combustor showed monotonic increase with the increase of $\alpha$ from zero uf to 0.7 then it kept an almost constant value. It is recommended to design IRRM's with high o.

\section{NOMENCLATURE}

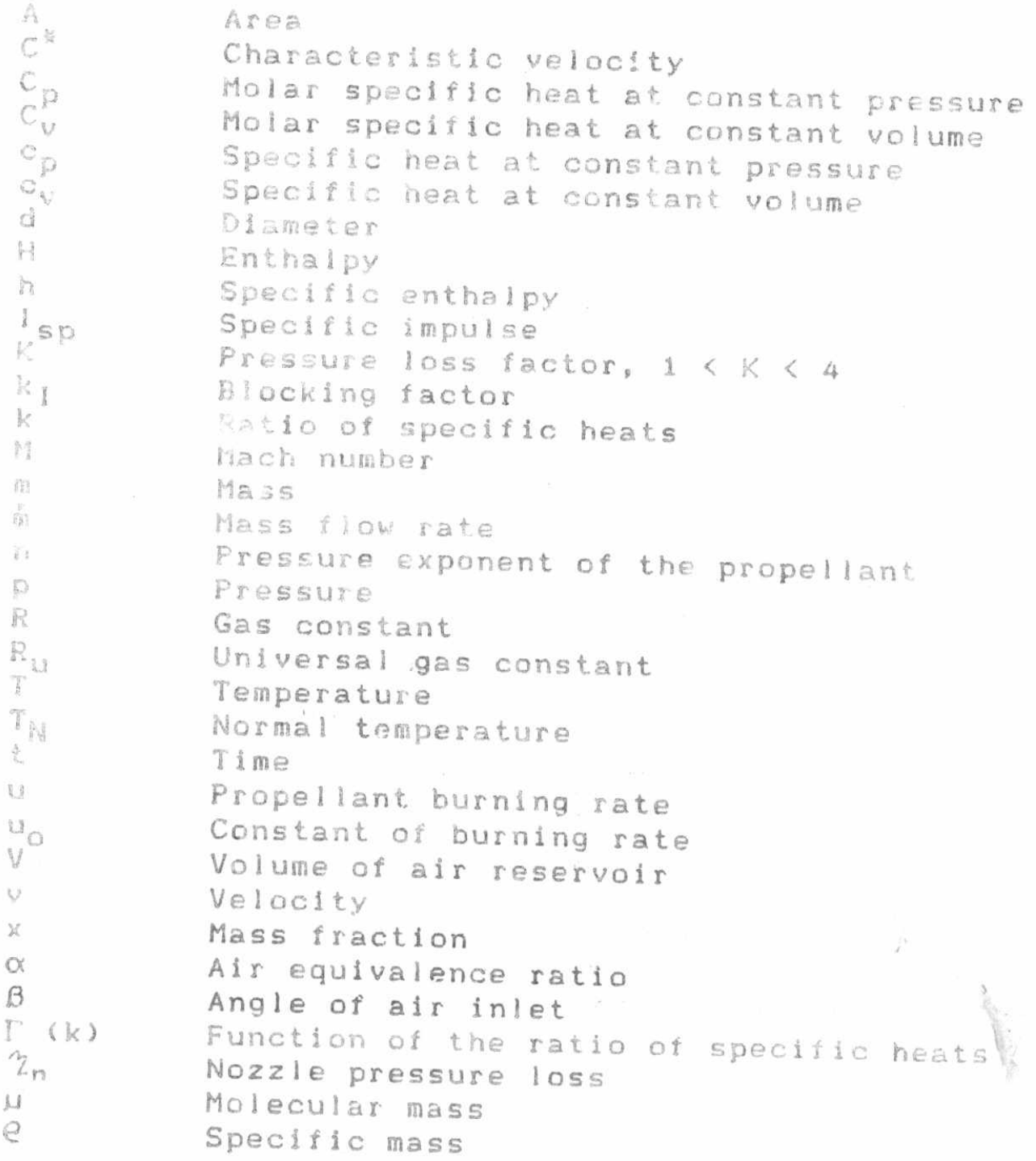




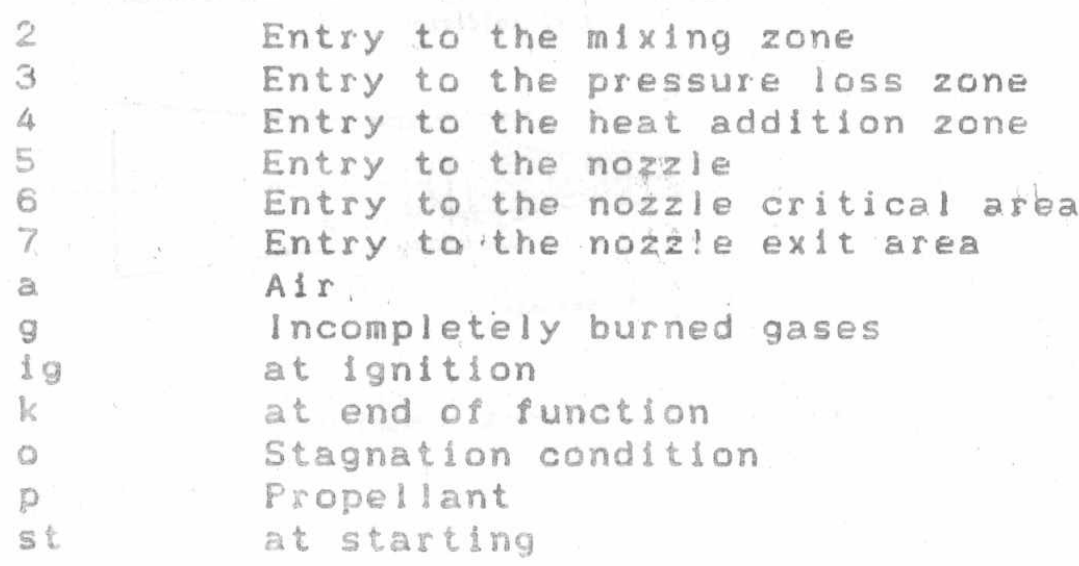

\section{REFEREHCES}

1. Thomas, N. Arthur and Thomas, JR, "New Generation Ramjet, A Promising Future", Astronautics and Aeronautics, Vol.18, Jan. 1980, pp 36-41, 71.

2. Ramos, J.1., "The Numerical Solution of Non-Prenixed Peactive Flous in a Sw1rl Combustor Model", Updated and. Enlarged Version of the International Conference of Numerical Methods in Non-Linear Problems, Barcelona Spaln, Apr $19-13,1984$.

3. Ghoniem, F. Ahmed, "Computational Methods in Turbulent Reacting Flow", Lectures in Applied Mathematics, Vol.24, 1986, Pp 199-239.

4. Arblb, H. A., Goldman, Y., Greenberg, J.B. and Timnat, Y.M., Numerical Model of High Intensity Conined Hydrocarbon Combustion", Combustion and Flame, Vol. 38 1980, pp 259-270.

5. Ramanujachary, V. et al., "Performance Analysts of Primary and Secondary System of a Rocket-Ramjet Engine Burning FuelRich Metallized Propellant", Fifth International Symposium on Alrbreathing Engines, Bangalore, India, (1981).

5. Hid, G. and Peterson, R., Mechanics and Thermodynamics of Propulsion", Addison Wesley, Massachusetts, 1965, p 220.

7. Sarhan, A. "An Experimental Investigation into the Performance of an Airbreathing Rocket Motor" M.Sc. Thesis. Military Technical college, Egypt, (1984).

6. Bárrere, M. "Rocket Propulsion", Elsevier Publishing Company. (1960).

9. Greenberg, J.B. and Timnant, Y.M., "Sudden Expansion Injection for Ram-Rockets", Fifth International Symposium on Airbreathing Engines. Bangalore, India, (1981).

10. Chen Da-ming et al., "Preliminary Experimental Study of in the Solid Propellant Rocket-Ramjet", Firth International Symposium on Airbreathing Engines, Bangalore, India, (1981). 


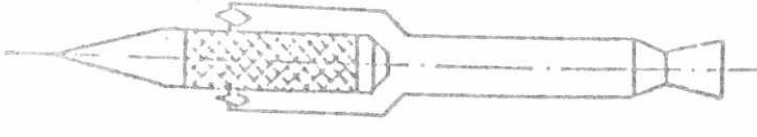

a Solld propeliant IRR.

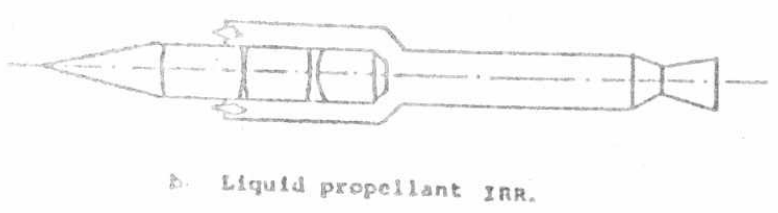

Flg. I Vartants of integral rocket ramjets

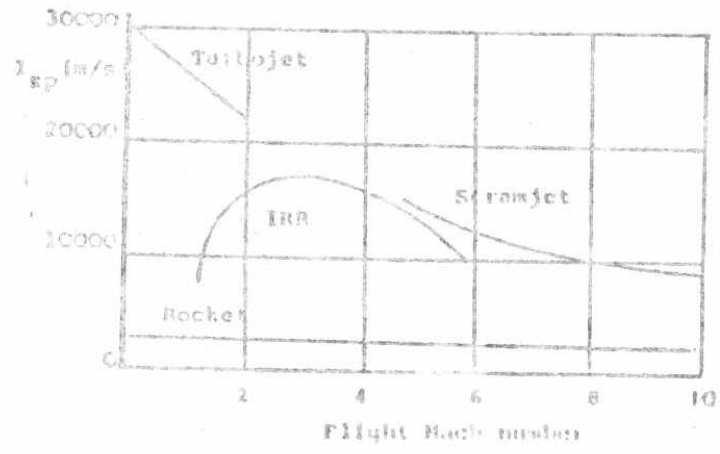

Fig.2 Spechito fimpulae/speed
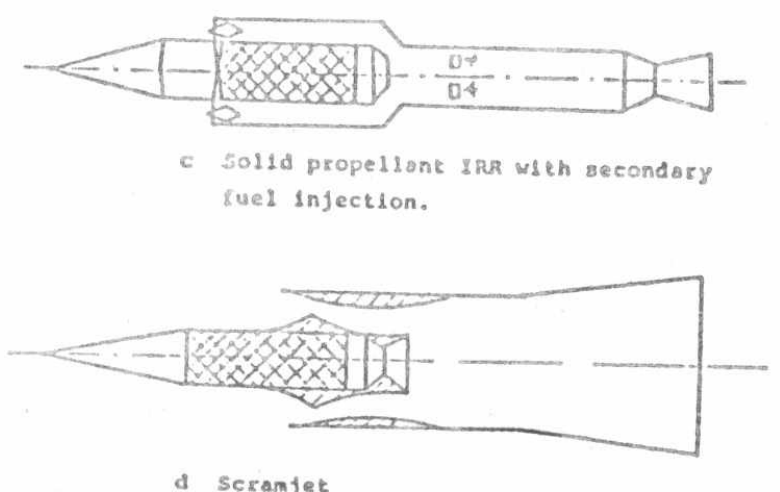

d Scranjet

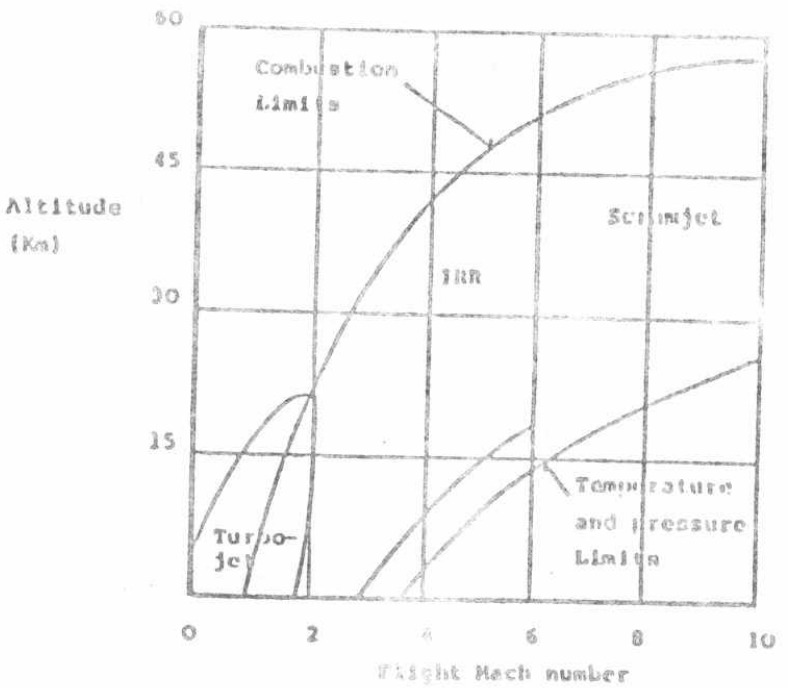

Fig.3 Speedraltitude

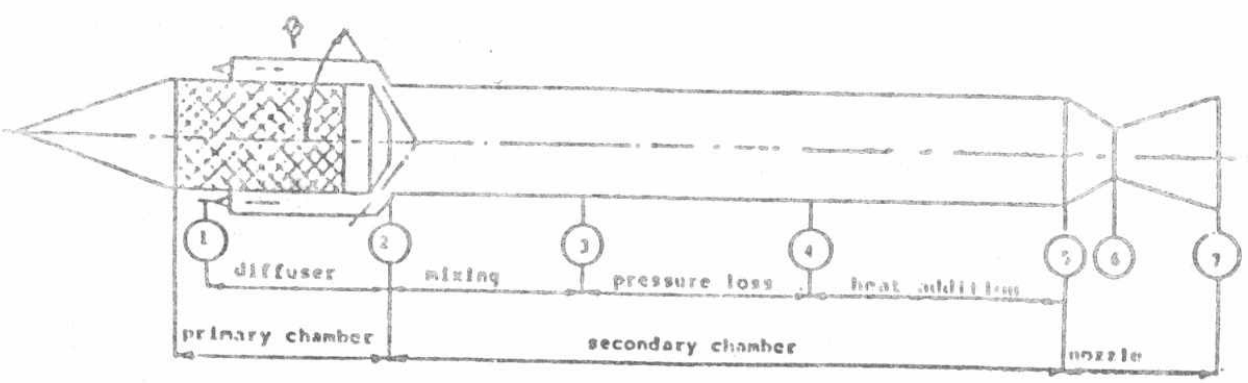

Fig. 4 Schematic sketch of solid propellant IRRM 


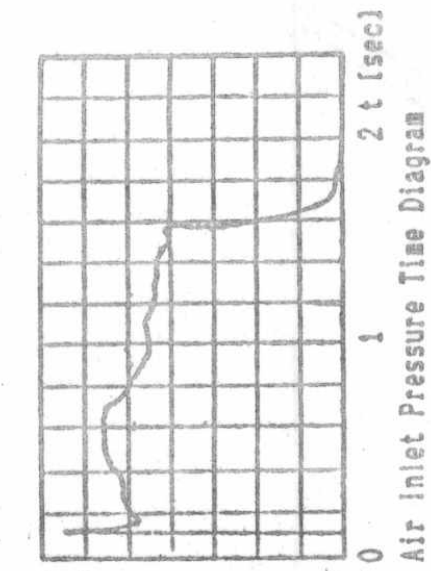

$\therefore$.

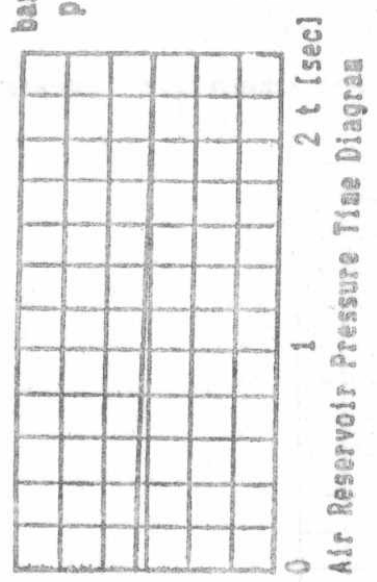
추 औ.
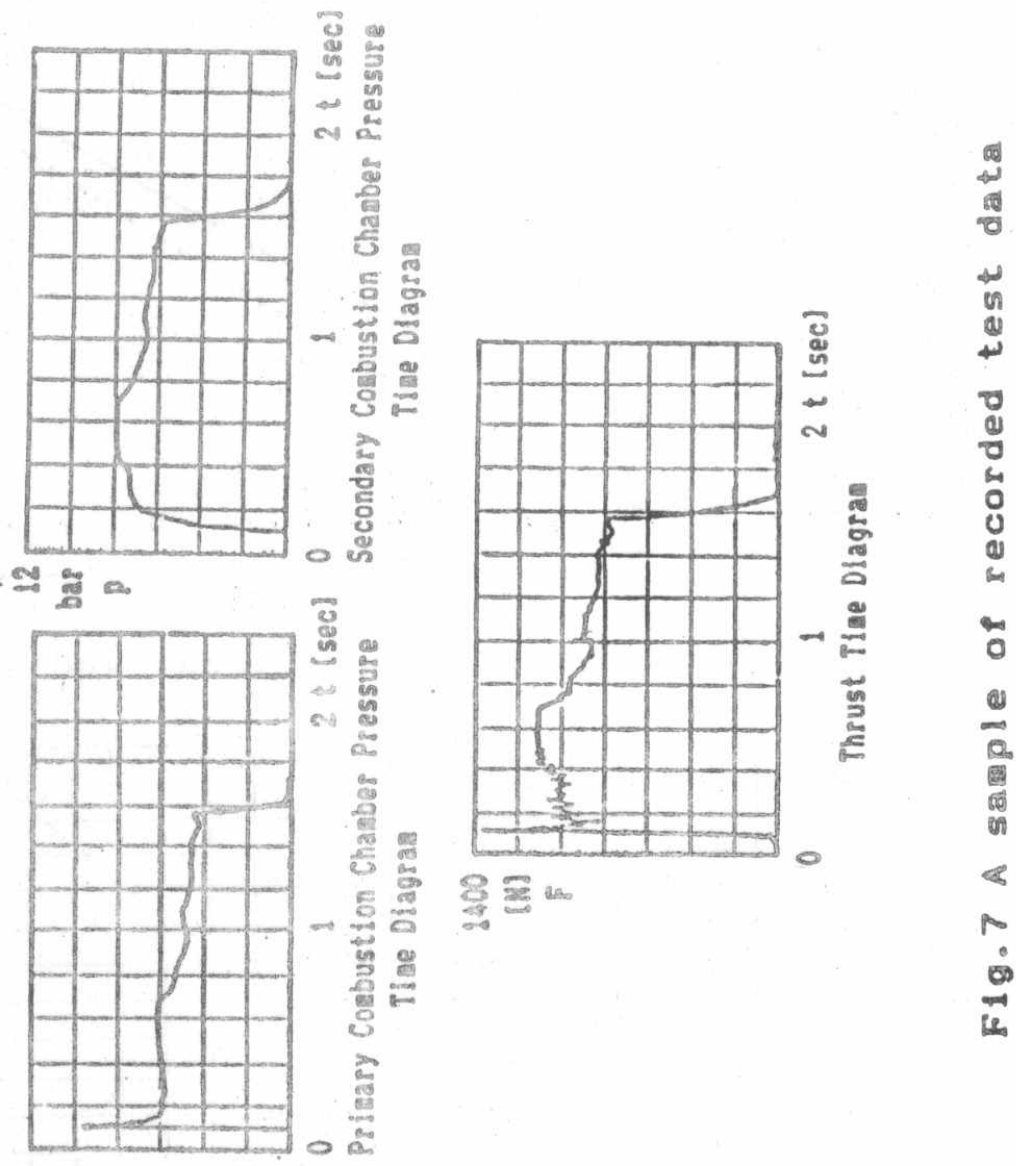

용 $a$

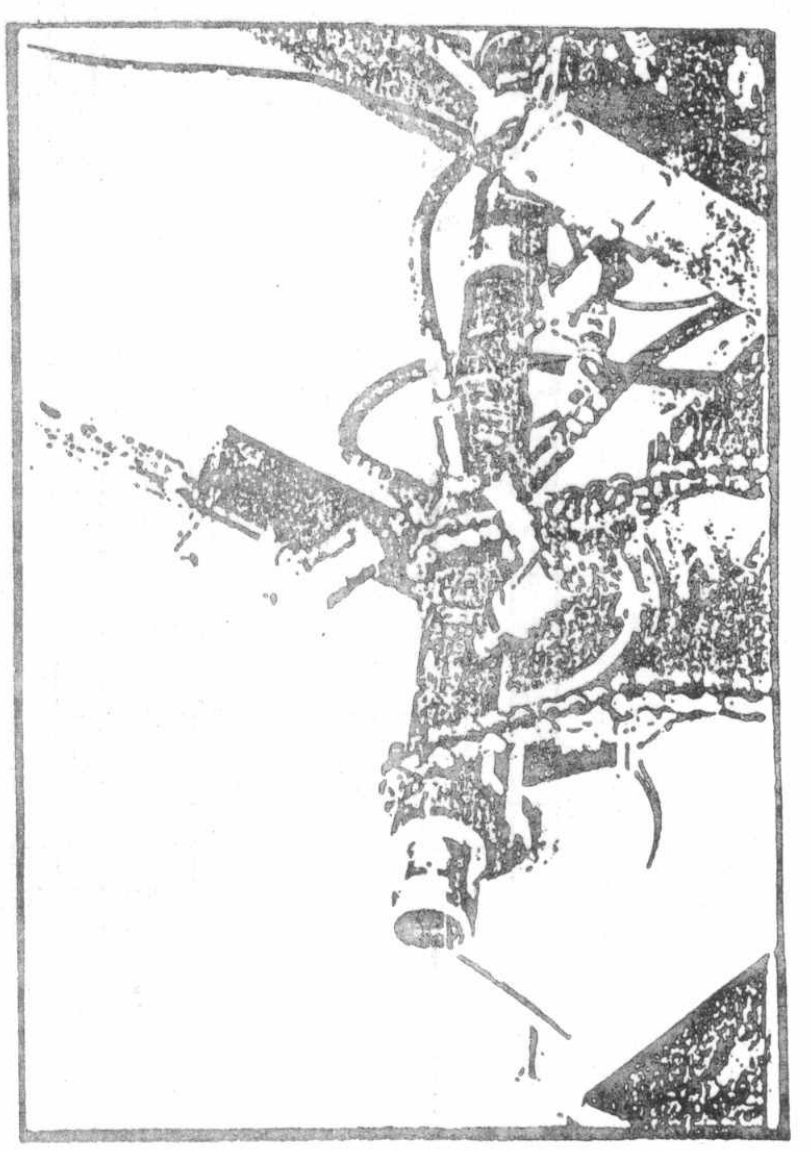

D 


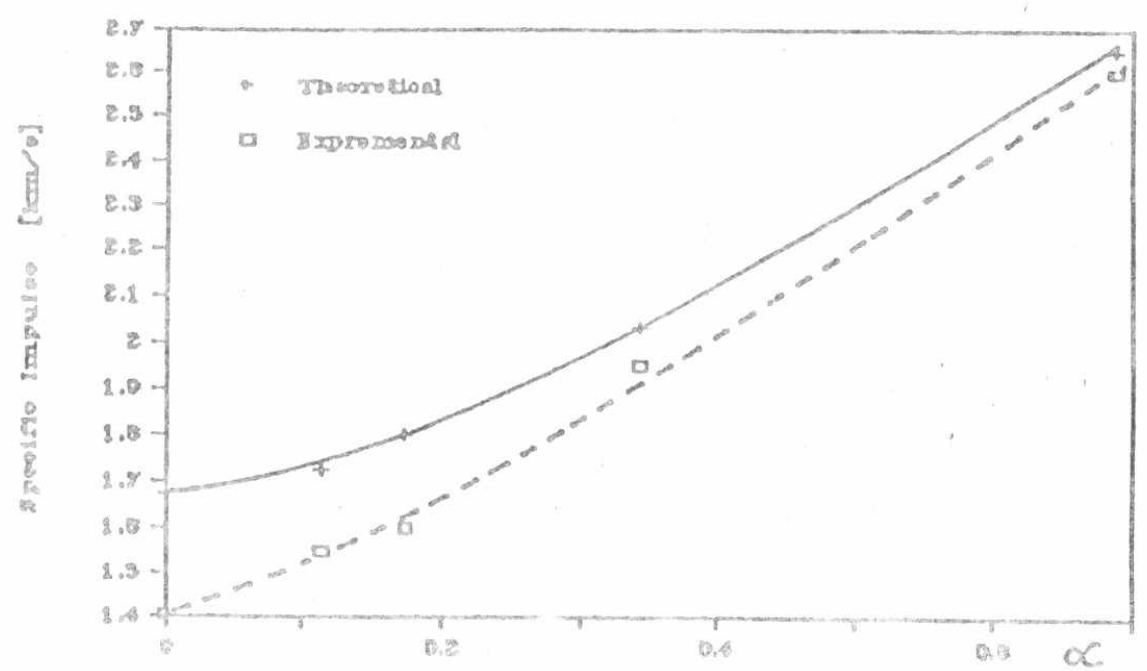

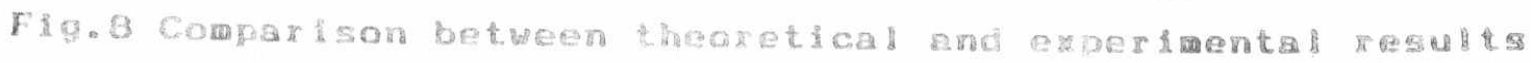

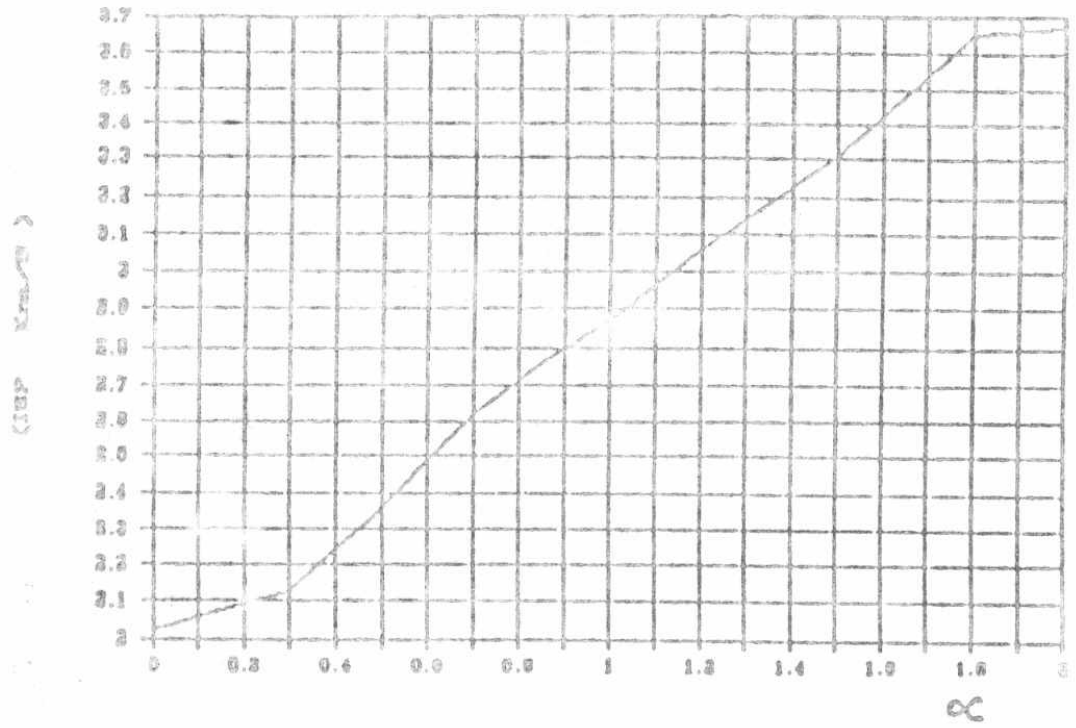

Fig.9 Specific lapulse us. air equivalence ratio

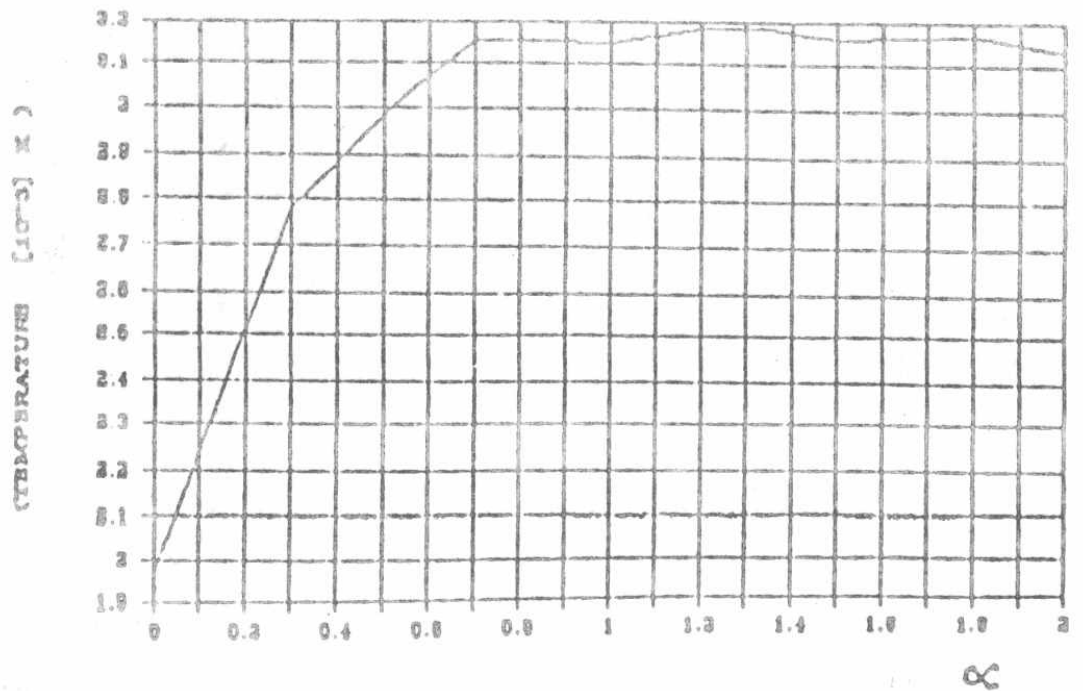

Fig.10 Adibatic flame temperature vs. aft equivalence ratio 